\title{
Eugène Labiche, La Dame aux jambes d'azur
}

\section{Valentina Ponzetto}

\section{(2) OpenEdition}

\section{Journals}

Édition électronique

URL : http://journals.openedition.org/studifrancesi/1410

DOI : 10.4000/studifrancesi. 1410

ISSN : 2427-5856

\section{Éditeur}

Rosenberg \& Sellier

\section{Édition imprimée}

Date de publication : 1 décembre 2015

Pagination : 617

ISSN : 0039-2944

\section{Référence électronique}

Valentina Ponzetto, «Eugène Labiche, La Dame aux jambes d'azur », Studi Francesi [En ligne], 177 (LIX I

III) | 2015, mis en ligne le 01 décembre 2015, consulté le 09 janvier 2021. URL : http://

journals.openedition.org/studifrancesi/1410; DOI : https://doi.org/10.4000/studifrancesi.1410

Ce document a été généré automatiquement le 9 janvier 2021.

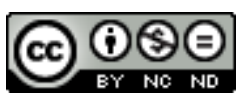

Studi Francesi è distribuita con Licenza Creative Commons Attribuzione - Non commerciale - Non opere derivate 4.0 Internazionale. 


\title{
Eugène Labiche, La Dame aux jambes d'azur
}

\author{
Valentina Ponzetto
}

\section{RÉFÉRENCE}

EUGÈNE LABICHE, La Dame aux jambes d'azur, dossier et notes par Olivier BARA, lecture d'image par Pierre-Olivier DouPHIS, Paris, Gallimard, 2015, «Folioplus classiques», pp. 124.

1 La Dame aux jambes d'azur est une petite pochade en un acte écrite par Labiche avec Marc Michel, le même collaborateur qui l'assiste pour certaines de ses pièces les plus célèbres, comme Un Chapeau de paille d'Italie ou L'Affaire de la rue de Lourcine. Elle a été représentée pour la première fois au théâtre du Palais-Royal en 1857 et a été composée spécifiquement pour les comédiens de ce théâtre, qui y apparaissent principalement dans leur propre rôle.

2 Il s'agit en effet d'une pièce fortement métathéâtrale, qui met en scène la troupe du Palais-Royal en train de répéter, au milieu de mille petites tracasseries cocasses, une pièce imaginaire intitulée justement La Dame aux jambes d'azur, qui a des allures de mauvais drame historique, voire de mélodrame, et qui est censée se passer dans une improbable Venise de la Renaissance et dans un décor de forêt. Les répétitions, interrompues presque à chaque réplique par des détails triviaux sur la vie privée des acteurs ou par des considérations sur les ficelles du spectacle, ne sont qu'un prétexte pour des scènes drôles et pour une encore plus réjouissante déconstruction du monde théâtral dans ces premières années du Second Empire.

3 Le riche dossier signé par Olivier Bara accompagne le lecteur à la découverte de ce monde, lui permettant de comprendre les enjeux d'une satire autrement difficiles à saisir, faute des référents culturels appropriés, et donc de goûter pleinement l'humour décapant de l'œuvre. Olivier Bara commence par situer la pièce dans le contexte littéraire et théâtral de son temps. D'une part, il évoque le climat de «fête impériale» 
qui domine les spectacles du Second Empire, dont Labiche et Offenbach représentent les figures de proue, et qui offre un éventail de genres bouffes, parodique et débridés: pochade, vaudeville ou opérette. De l'autre, il retrace le déclin et les survivances du théâtre romantique et l'essor du nouveau drame d'idées ou comédie sérieuse avec Dumas fils et Émile Augier. L'ironie de Labiche prend tous ces genres pour cibles. Une deuxième partie du dossier analyse donc la dimension intertextuelle et parodique de $L a$ Dame aux jambes d'azur, dont le drame romantique à la Victor Hugo est la cible principale. Une troisième partie suit enfin l'histoire du texte à travers ses différents états et variantes, dues aux remaniements successifs d'une première version de 1853 à celle définitive de 1857, aux interventions de la censure, ici très légères, et surtout à l'intégration progressive des données scéniques comme les costumes, les positions des personnages sur le plateau, l'intervention sur scène du machiniste.

4 Complètent le dossier une petite anthologie de textes comprenant des exemples de théâtre dans le théâtre, de Shakespeare à Pascal Rambert, une chronologie biobibliographique sur «Labiche et son temps» (1815-1888) et un commentaire sur le décor de forêt du Théâtre de la reine au Petit Trianon par Pierre-Olivier Douphis.

5 Simple et clair sans jamais devenir simplificateur, didactique dans le plus noble sens du terme, ce petit volume a beaucoup à apprendre à toutes sortes de lecteurs, en plus de nous faire découvrir une pièce oubliée, au charme suranné et intemporel à la fois d'un «envers du décor» et d'une critique théâtrale mise en action. 